Article

\title{
Sustainable Development of Foodservices under Uncertainty
}

Sohrab Abdollahzadeh (I)

check for

updates

Citation: Abdollahzadeh, S. Sustainable Development of

Foodservices under Uncertainty. Sustainability 2021, 13, 5182. https:// doi.org/10.3390/su13095182

Received: 4 December 2020 Accepted: 31 December 2020 Published: 6 May 2021

Publisher's Note: MDPI stays neutral with regard to jurisdictional claims in published maps and institutional affiliations.

Copyright: (C) 2021 by the author. Licensee MDPI, Basel, Switzerland. This article is an open access article distributed under the terms and conditions of the Creative Commons Attribution (CC BY) license (https:/ / creativecommons.org/licenses/by/ $4.0 /)$.
Faculty of Industrial Technologies Department, Urmia University of Technology, Urmia 5716693187, Iran; s.abdollahzadeh@uut.ac.ir; Tel.: +98-9141-417-328

\begin{abstract}
The purpose of the present study is to provide an approach to identify and investigate the effects of each factor on the development of foodservices in cities. The factors influencing the development of foodservices are extracted. Since there are many factors, interpretive structural modeling is used to rate the key factors. Foodservice improvement action plans are determined by experts and ranked using the slack-based data envelopment analysis method. "Area facilities" and "government support" are the main factors in the development of foodservice units in cities. Factors such as the culture of the region, the size of the units, and systematic recycling of raw materials are also priorities and should be emphasized. Improvement action plans including the action plans of "building the main infrastructure" and "government protection approval" are the priority. According to the findings of this study, foodservices and their development in West Azerbaijan province in Iran need government efforts to provide infrastructure facilities, legal support of units, and create a culture of healthy nutrition in the community. Reconstruction of foodservices and the use of recyclables should also be put on the agenda.
\end{abstract}

Keywords: sustainable; foodservices; interpretive structural modeling (ISM); slack-baseDEA (S-DEA); uncertainty

\section{Introduction}

Presently, humans are constantly struggling and overworked, with little opportunity for home cooking; therefore, foodservices play an important role in meeting this need. Restaurants, fast-food restaurants, home-cooked foodservices, and coffee shops each satisfies this need somehow. Moreover, due to the high popularity of these centers, there has been a great deal of competition between them to attract more customers. Food retailers are competing fast, and each is trying to attract more customers and make more money by providing special offers and cheaper and healthier alternatives. However, traditional restaurants still have a large share of catering and have their own customers. Food is essential for human survival, and therefore food safety is a fundamental human right. Millions of people around the world are at risk from unsafe food. Food manufacturers, distributors, and food service companies are primarily responsible for people's health [1]. Consumers must be alert and literate and choose their food service consciously. Also, government agencies must enforce food safety laws to protect public health [2]. Due to the pandemic of COVID-19 and its various consequences, especially in the food chain, the importance of food safety in food services has become more apparent [3].

Eating out is one of the most popular leisure activities among Europeans, resulting in a booming restaurant and foodservice industry. Food services, also known as catering services, refers to all services for out-of-home consumption of food and drink, including restaurants, cafés, bars, takeaway, food delivery, contract catering, cafeterias, and other food vendors. In Western Europe, the consumer foodservice market was valued at 427 billion euros in 2016 and the Eastern European market at 45.6 billion euros. Restaurants are possibly the main outlet type used by consumers in the foodservice industry, from fullservice "sit down" restaurants to limited service and casual dining establishments [4]. The 
desire to eat outdoors is raising around the world [5]. For example, the growth trend of eating at home and outdoors in the United States from 1960 to 2019 is shown in Figure 1.

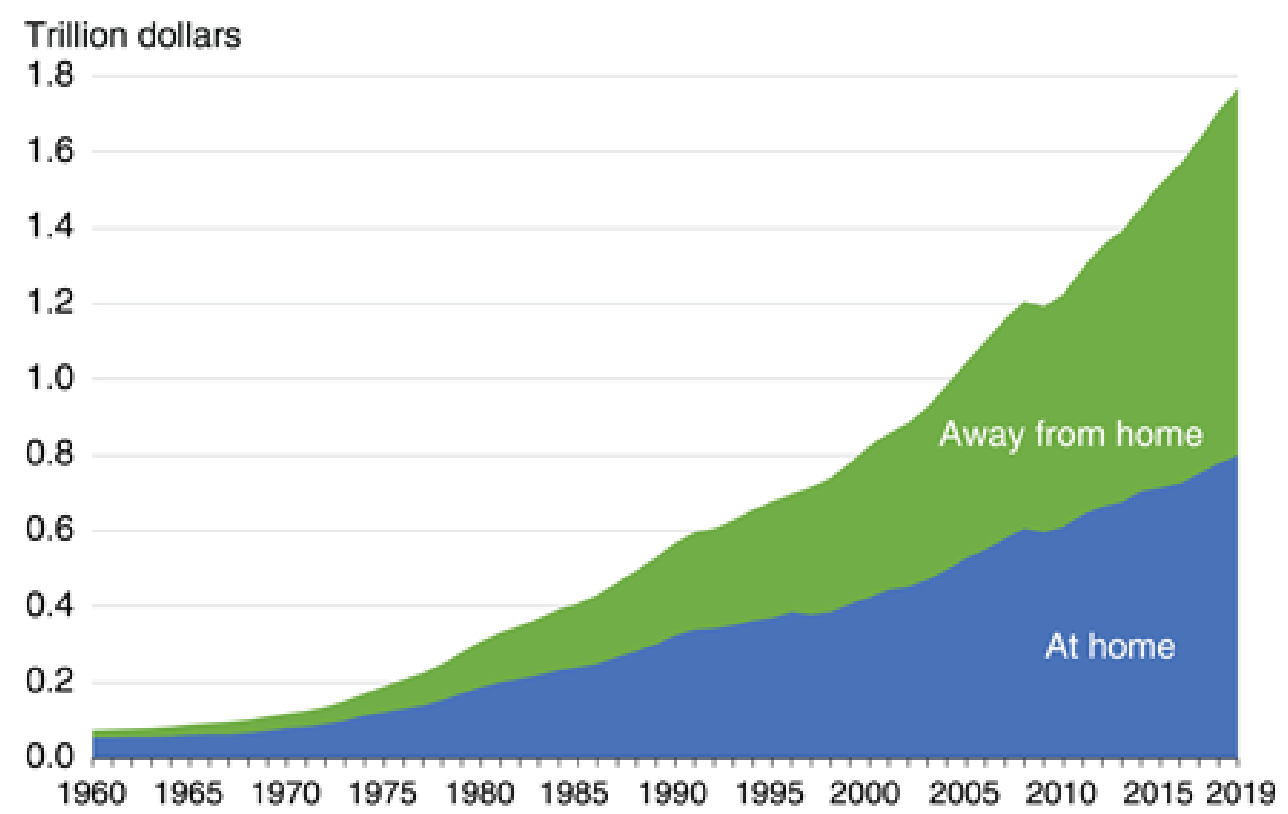

Figure 1. U.S. food-away-from-home spending continued to outpace food-at-home spending in 2019.

The growth trend of this phenomenon in developing countries, including Iran, is more than developed countries. Eating out is also becoming common in Iranian society. Iranians spend more than 17,000 billion tomans (approximately 860 million Dollars) annually on ready-to-eat food. In 2018, every Iranian household spends $\$ 180$ per year, which is about $2 \%$ of the total household expenditure, to buy food outside the home. During the ten years from 2008 to 2018, the cost of Iranian households to buy food outside has increased more than 5 times [5]. These trends show the importance of food service development in Iran more than ever.

Foodservices represent the culture and customs of an area and are of great importance. The importance of these centers has grown to such an extent that a phenomenon known as "food tourism" has emerged as a subcategory of the tourism industry. Traveling for food has become one of the motives for tourism in many countries of the world [6]. Iran has the potential to benefit from this industry because of its numerous tourism and customs potentials. In addition, the dramatic increase in foodservice centers, especially restaurants and cafés, makes the need for further research in this area more pronounced. However, the factors that have contributed to the development of foodservices in developing countries have not been addressed as expected.

Considering that Iran is one of the developing countries and the change in living and working conditions of people has caused a significant growth of food services in the last decade. As a result, due to Iran's favorable climatic, geographical, demographic conditions, it has provided the potential for further development of food services.

According to the above, the sustainable development of these foodservices is important. In this regard, it is necessary to extract the key factors affecting the success of these units and identify the root factors. Also, to reduce uncertainty in managers' decisions, improvement action plans (IAPs) should be developed and prioritized by experts.

The current study investigates the factors affecting foodservices for the first time using the combination of interpretive structural modeling (ISM) and slack-base-data envelopment analysis (DEA) (S-DEA) methods. This study has ranked the Influential factors and rank the foodservices IAPs. First, important factors affecting the development of foodservices are extracted from written sources and expert opinion. Then, the effective factors and the logical relationships between them are determined according to the ability of the ISM 
method to identify and summarize the relationships among elements. In the final step, the factors, and the relationship between them are analyzed and the main factors along with the relationship between them are introduced in foodservices using the Impact Matrix Cross-Reference Multiplication Applied to a classification (MICMAC) method. Then, the practical IAPs provided by the experts are ranked by the S-DEA technique.

The main objectives of this research are as follows:

- Identifying key factors affecting the sustainable development of foodservices, analyzing the relationships between them at different levels and determining the root factors using the ISM method.

- Develop IAPs for root factors using experts' opinion and prioritize programs using the S-DEA method to reduce decision uncertainty.

By identifying the root factors affecting the development of food services, and providing IAPs, a basis will be created for the development of strategies and improvement programs for their sustainable development.

The rest of the research is organized as follows. Section 2 provides an overview of the literature and research conducted in the field of foodservices with a focus on data envelopment analysis and ISM method. Then, Section 3 presents the research method and a further explanation of the proposed method. Section 4 describes the case study and the importance of the study area. Section 5 analyzes the results. Finally, Section 6 presents the results of the research and suggestions for future research.

\section{Literature Review}

Aksoydan (2007) examined the factors influencing the choice of customers for the dining unit in Ankara, Turkey. Factors examined were cleanliness, indoor dining environment, service, and food. The results showed that the most important factor in customer selection is the hygiene and cleanliness of the restaurant, food, dishes and cutlery, service personnel, toilets, and kitchen [7].

Sagheer et al. (2009) identified and analyzed the critical factors affecting standards compliance and their impact on the developing food industry in India using the ISM method. Their analysis showed that the food industries of these countries are being destroyed while complying with standards because of the costs involved in setting up systems and procedures. Consequently, supportive measures should be used, including linking domestic and international markets, strengthening institutional structures, strengthening legal and regulatory systems by governments [8].

Kumar et al. (2015) analyzed some of the important variables of the agile manufacturing system that lead to system agility and designed the relationships between them using ISM. Finally, weights were determined for the existing relationships by firm managers and the firm agility factor using the graph-theoretical matrix approach [9].

Bag and Anand (2015) used ISM and MICMAC analysis to identify the interrelationships between leading barriers to sustainable supply chain design. Their study has paid particular attention to the food-processing sector. The variables identified by the research help decision-makers to successfully design a sustainable network by removing high-level barriers [10].

Chaudhuri et al. (2016) identified dangerous confidential factors affecting the food supply chain and expressed important functional measures. This study has used a fuzzy interpretive structural model to quantify relationships and determine indirect and general relationships. The analysis showed that working with logistics providers and concluding mutual contracts with them can significantly reduce risks and lead to revenue growth [11].

In one study, Sajid et al. (2017) defined the relationships between risk factors and their integration with the target objective analysis approach in biodiesel systems. They used an ISM to identify the relationships between risk factors; on the other hand, they used the Bayesian network method to determine the dependence power and perform risk analysis [12]. 
Darbari et al. (2018) identified significant barriers to sustainability in foodservices using ISM and categorized barriers based on their driving power and dependence. Their proposed integrated structural model can be used as a tool by decision-makers to systematically overcome the barriers and formulate sustainability strategies in foodservices in understanding the interrelationships and interdependencies between barriers to release and implementation of sustainability in food supply chains [13].

Naeini, et al. (2019) comprehensively evaluated the competitive advantage as well as designed and explained a hybrid model of competitive advantage based on capital theory and competitive intelligence in the Iranian food industry using ISM. Their research findings indicate that firms are established by managers through a fledgling capital and high competitive intelligence, attaining a competitive advantage in the market [14].

In recent years, the ISM has been widely used, especially in the field of management. For example, an ISM has been used to analyze the basic concepts of the management excellence model with risk-based thinking [15]. The aim of this study was to identify a set of factors affecting the intention to buy halal food and to measure the relative amount of these factors in buying halal food among Muslim consumers in India [16].

According to the literature review, there are too many significant factors affecting foodservices and techniques such as DEA usually do not give acceptable results. Consequently, crucial, and key factors must be selected. However, ISM is a good way to identify key factors in different areas including foodservices, this model has not been used so far to identify important factors influencing the development of foodservices. Moreover, the S-DEA technique has been used as an appropriate IAPs for ranking foodservices development.

\section{Methodology}

\subsection{ISM Method}

The ISM method was developed by Warfield, which shows the relationship between factors and their levels that are classified according to their driving power and dependence [17]. This model is a well-known method for identifying and summarizing the relationships between particular elements that define a problem [18]. This model is an interactive learning process that consists of a set of different and independent elements linked to a systematic comprehensive system. The model is constructed in such a way that the structure of a problem is complicated in the form of a precise pattern, graphically and descriptively. According to group judgment, this is a modeling technique that is depicted as having special relationships and overall structure in a graphical model. ISM is mainly intended as a group learning process [19].

This method starts by identifying the elements of the problem and extends to a group problem-solving method. Then, a content-dependent relationship is selected. A structural self-interaction matrix is developed by deciding on the set of lists and the contextual relationship based on binary comparisons of elements. Next, the structural self-interaction matrix is transformed into a reachability matrix and its transitivity is examined. A matrix model is obtained when the transitivity is completed. Finally, element classification and ISM extraction are obtained [20]. The various stages of ISM are as follows [21]:

\subsubsection{Identification of Individual Cognitive Factors (ICFs)}

Preparing a list of criteria or elements: A content relationship is defined between them according to each pair of criteria using the criteria or variables identified. Content Relationship means the conceptual relationship between the components of the system in a way that is tailored to the goals of the system in terms of meaning and content.

\subsubsection{Structural Self-Interaction Matrix}

This is a square matrix whose members are the same criteria introduced. These criteria have been extracted using expert opinions based on various management techniques such as brainstorming, nominal group, etc., and criteria in previous research that have been approved by experts. The entries of this matrix are $\mathrm{V}, \mathrm{A}, \mathrm{X}$ and $\mathrm{O}$ as follows: 
$\mathrm{V}$-Dimension " $\mathrm{i}$ " leads the dimension " $\mathrm{j}$ "

A-Dimension " $\mathrm{j}$ " leads the dimension " $\mathrm{i}$ "

$X$-Dimension " $i$ " and dimension " $j$ " lead to each other

$\mathrm{O}-$ Dimensions " $\mathrm{i}$ " and " $\mathrm{j}$ " are unrelated.

\subsubsection{Individual Reachability Matrix}

Develop a reachability matrix using a structural self-interaction matrix: This matrix is examined for transitivity. Transitivity is the content relation of a fundamental hypothesis in ISM. The structural self-interaction matrix is transformed into a $(0,1)$-matrix called the initial reachability matrix. The rules for this substitution are as follows:

- If the $(i, j)$ cell in the structural self-interaction matrix (SSIM) is $V$, then the $(i, j)$ cell in the reachability matrix becomes 1 and the $(j, i)$ cell becomes 0 .

- If the $(i, j)$ cell in the SSIM is A, then the $(i, j)$ cell in the reachability matrix becomes 0 and the $(j, i)$ cell becomes 1 .

- If the $(i, j)$ cell in the SSIM is $X$, then the $(i, j)$ cell in the reachability matrix becomes 1 and the $(j, i)$ cell also becomes 1 .

- If the $(i, j)$ cell in the SSIM is $O$, then the $(i, j)$ cell in the reachability matrix becomes 0 and the $(j, i)$ cell also becomes 0 .

\subsubsection{Final Reachability Matrix}

This matrix is obtained for the criteria considering the transitive relation until the initial reachability matrix is adapted. For this purpose, the initial matrix must be raised to the power $\mathrm{k}+1$ so that a steady state is reached $\left(M^{K}=M^{K+1}\right)$. Hence, some 0 elements will also be converted to 1 , represented as $1^{*}$.

After constructing the relationship matrix or initial reachability matrix, the final reachability matrix must be obtained using Equation (1).

$$
M=D+I M^{*}=M^{K}=M^{K+1}, K>1
$$

" $I$ " is identity matrix.

The final matrix is raised to power until the above situation takes place. The resulting matrix is the final reachability matrix. The matrix "raising to power" operation must be in accordance with the Boolean rule. The number of $1 \mathrm{~s}$ in the first row indicate lines or effects that are derived from the first criterion. The number of $1 \mathrm{~s}$ in the first column indicate the effects that are placed on the first criterion. "Source" is the component that affects all the components of the system but is not affected by any component.

\subsubsection{Establishment of ISM}

Divide the reachability matrix into different levels:

Antecedent and Succedent Sets: Each of the system components (criteria) has two different sets, namely antecedent (A) and succedent or reachability (R), which play a central role in the final matrix structure as well as system design. The antecedent set of each criterion includes the criteria that lead to or affect that criterion. In other words, the criteria with a 1 in front of them in the column corresponding to a criterion are the antecedent set on that column criterion. On the contrary, the succedent set represents the criteria that are affected by a system criterion or component. The succedent set is also called the reachability set.

Criterion leveling: Criterion leveling begins after obtaining antecedent and succedent sets. The common set is obtained by acquiring an affinity for these two sets. Elements whose common set is the same as the reachability set are assigned the first level of priority. The level of all elements is determined by removing these elements and repeating this process for the other elements.

Plotting: Draw a directed graph based on the relationships defined in the reachability matrix and the elimination of the transitivity relations. 
First, we sort out the criteria according to the top-down priority based on the level. The structural model is plotted by nodes and lines using a matrix derived from a received matrix sorted by levels. If there is a relation from $i$ to $j$, it is indicated by an arrow from $i$ to $j$.

Convert the final diagram by replacing the names of variables or criteria instead of nodes into an ISM.

The ISM developed in plotting will be revised to ensure that it is compatible in terms of content. Required corrections are made in case of incompatibility.

\subsubsection{MICMAC Analysis}

The purpose of this analysis is to identify and analyze the influence and the dependence of variables. In this analysis, the variables are divided into four categories according to driving power and dependence: 1 . Autonomous variables with weak driving power and dependence. These variables are relatively unrelated to the system and have low and poor communication with the system. 2. Dependent variables with low driving power but at the same time high dependence. 3. Linkage variables with high driving power and high dependence. These variables are non-static because any changes in them can affect the system and eventually the system feedback can change these variables again. 4 . Independent variables with strong driving power but also weak dependence.

\subsection{S-DEA Method}

DEA is a method for evaluating decision-making units (DMUs) [22]. DEA model assigns number 1 to efficient decision-making units and numbers less than 1 to inefficient units [23]. The DEA has been applied in different areas, including: measuring investment efficiency for renewable energy [24], evaluating the technical efficiency of units with different expertise [25]. DEA is a non-parametric method for evaluating the relative performance of a set of DMUs. The model used in this study is a type of DEA called (SBM). Input-oriented DEA models consider a possible decrease in inputs with a constant level of outputs and output-oriented models consider a possible increase in inputs with a constant level of inputs. S-DEA model takes into account both the possible input reduction as well as the output increase and is based on input and output [26].

In this study, the S-DEA method was used to rank the proposed IAPs. This is performed by identifying and considering the impact of IAPs on each of the factors and calculating the effectiveness of the IAPs.

\section{Proposed Approach}

This research is descriptive by purpose and applied by results. This is a mixed research method by data type. The statistical population of the study consists of 8 foodservices experts from universities as well as managers and owners of foodservices in West Azerbaijan province. Data collection tools include interviews and a questionnaire. Figure 2 presents the conceptual model of research. 


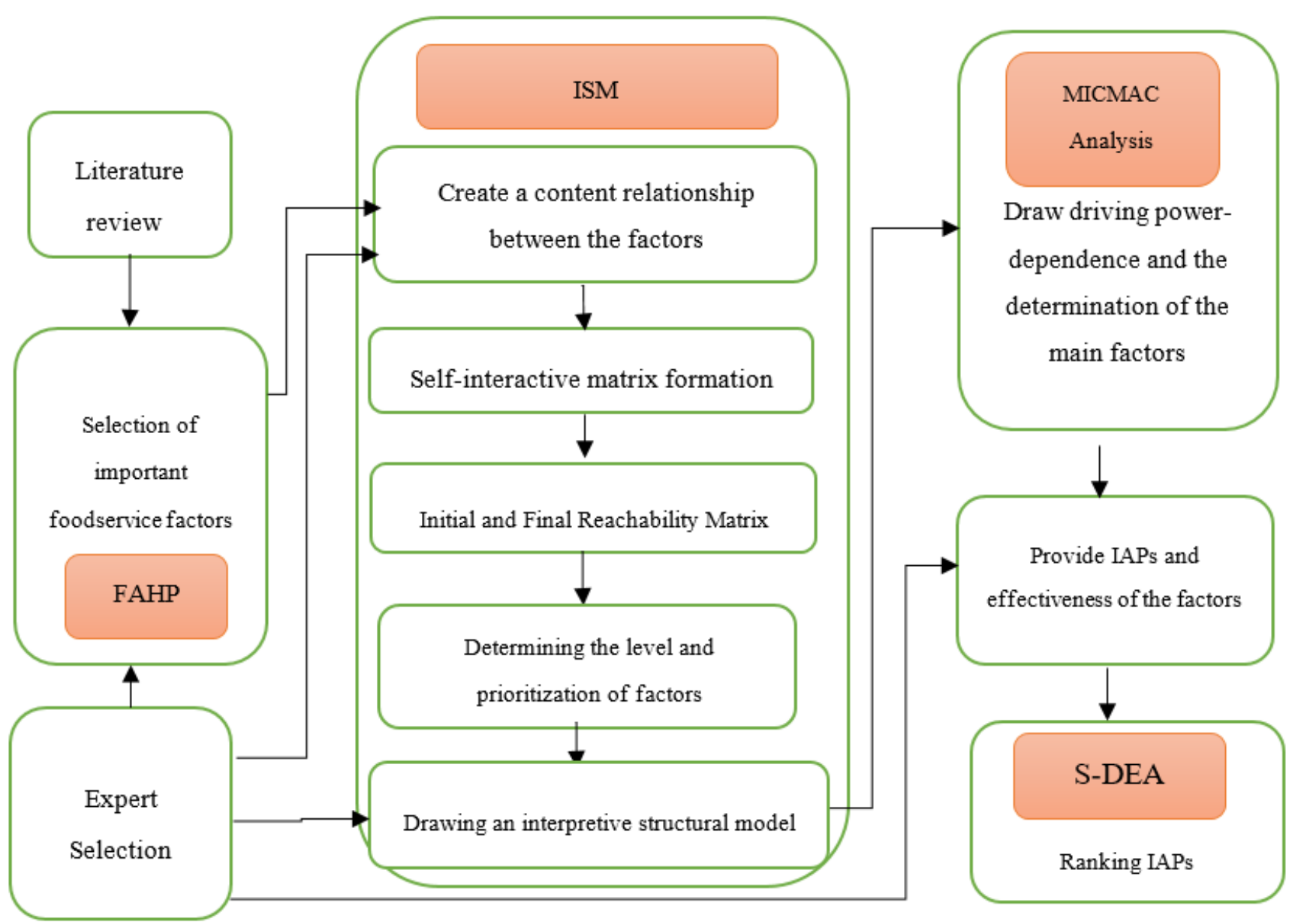

Figure 2. Conceptual framework of research.

\section{Results}

To validate the proposed model, a case study was conducted on the foodservices of one of the cities of Iran. The steps of this case study are quite consistent with the proposed model.

\subsection{Select Experts and Important Factors}

Step 1: the factors affecting the success of foodservice units are extracted using the literature review. 8 people were selected, including 3 university professors in foodservice, 3 foodservice managers, and 2 foodservice experts. Due to many influencing factors, the factors must be monitored, and the most important factors should be selected. 34 factors were identified in three groups, i.e., social, environmental, and green to investigate the factors influencing the success and progress of foodservices, using factors found in previous research [27-29]. Among the factors, demographic factors are also included. The Fuzzy Analytic Hierarchy Process method (FAHP) is selected using the research background due to the uncertainty in the experts' points of view. Criteria such as: environmental sustainability, food safety, economic development, customer orientation, and legal requirements were used to select the factors. Finally, 17 factors were selected for the current investigation. These factors are listed in Table 1 in the order of each section.

\subsection{Plot ISM}

Step 2: Using the DEA method does not produce acceptable results due to the large number of influencing factors identified in the first stage. Consequently, factors are leveled and the relationship between the factors at each level is determined and the associated diagram is drawn. This step leads to the identification of root factors. 
Table 1. Factors affecting foodservice success.

\begin{tabular}{|c|c|c|c|c|c|}
\hline No. & Social Factors & No. & Environmental Factors & No. & Green Factors \\
\hline $\mathrm{F} 1$ & Customer loyalty & F7 & competition & F14 & Environmental damage \\
\hline $\mathrm{F} 2$ & Area culture & F8 & Foodservice location & F15 & use of organic materials \\
\hline F3 & Customer satisfaction & F9 & Foodservice size & F16 & Waste separation \\
\hline $\mathrm{F} 4$ & government pressure or support & F10 & Decoration & \multirow{4}{*}{ F17 } & \multirow{4}{*}{ use of recyclable materials } \\
\hline F5 & Advertisement & F11 & Area facilities & & \\
\hline \multirow{2}{*}{ F6 } & \multirow{2}{*}{ Tax } & F12 & Staff behavior & & \\
\hline & & F13 & managers' policies & & \\
\hline
\end{tabular}

The ISM is performed, and the level and relationship diagrams are plotted after selecting the most important factors. In the survey, experts were asked to determine the relationships between factors in terms of the absence of a relationship, the existence of a one-sided relationship, and the existence of a two-sided relationship by comparing them by pair. After the survey, a structural self-interaction matrix and an upper triangular matrix were formed using the survey mode. Table 2 shows the self-interaction matrix of the research case study.

Table 2. Self-Interaction Matrix.

\begin{tabular}{|c|c|c|c|c|c|c|c|c|c|c|c|c|c|c|c|c|c|}
\hline 7 & F1 & F2 & F3 & F4 & F5 & F6 & F7 & F8 & F9 & F10 & F11 & F12 & F13 & F14 & F15 & F16 & F17 \\
\hline $\mathrm{F} 1$ & & 0 & -1 & 0 & 0 & 0 & 0 & 0 & 0 & 0 & -1 & 0 & -1 & 1 & 1 & 0 & 0 \\
\hline F2 & & & 0 & 0 & 0 & 0 & 0 & 0 & 0 & 0 & -1 & 1 & 1 & 1 & 0 & 0 & 0 \\
\hline F3 & & & & 0 & -1 & 0 & 0 & 0 & 0 & 1 & 0 & 0 & -1 & -1 & -1 & -1 & 0 \\
\hline F4 & & & & & 0 & 1 & 0 & 0 & 0 & 0 & 1 & 0 & 0 & 1 & 0 & 0 & 0 \\
\hline F5 & & & & & & 1 & 0 & 0 & 0 & 1 & 0 & 0 & 0 & 1 & 0 & 0 & 0 \\
\hline F6 & & & & & & & 0 & -1 & 0 & 0 & 0 & 0 & 0 & 1 & 0 & 0 & 0 \\
\hline F7 & & & & & & & & 0 & 1 & 1 & 0 & 0 & 0 & 0 & 1 & 0 & 1 \\
\hline F8 & & & & & & & & & -1 & 1 & 0 & 0 & 0 & 0 & 0 & 0 & 0 \\
\hline F9 & & & & & & & & & & 0 & 0 & 0 & 0 & -1 & 0 & -1 & -1 \\
\hline F10 & & & & & & & & & & & -1 & -1 & -1 & -1 & 2 & -1 & 0 \\
\hline F11 & & & & & & & & & & & & 0 & 0 & 2 & 1 & 0 & 0 \\
\hline F12 & & & & & & & & & & & & & 0 & -1 & 2 & 0 & 0 \\
\hline F13 & & & & & & & & & & & & & & -1 & 2 & 0 & 0 \\
\hline F14 & & & & & & & & & & & & & & & 2 & 1 & 1 \\
\hline F15 & & & & & & & & & & & & & & & & 2 & 0 \\
\hline F16 & & & & & & & & & & & & & & & & & 0 \\
\hline F17 & & & & & & & & & & & & & & & & & \\
\hline
\end{tabular}

After the self-interaction matrix is formed, the initial reachability matrix is formed according to the instructions given in Table 3.

After the initial reachability matrix is formed, the final reachability matrix is formed according to Table 4. As mentioned earlier, some 0 elements that have been converted to 1 are shown in the table with the symbol *. Driving power and dependence power indicate the degree of independence and dependence of the criteria, respectively. 
Table 3. Initial Reachability Matrix.

\begin{tabular}{ccccccccccccccccccc}
\hline & F1 & F2 & F3 & F4 & F5 & F6 & F7 & F8 & F9 & F10 & F11 & F12 & F13 & F14 & F15 & F16 & F17 & $\begin{array}{c}\text { Driving } \\
\text { Power }\end{array}$ \\
\hline F1 & 0 & 0 & 0 & 0 & 0 & 0 & 0 & 0 & 0 & 0 & 0 & 0 & 0 & 1 & 1 & 0 & 0 & 2 \\
\hline F2 & 0 & 0 & 0 & 0 & 0 & 0 & 0 & 0 & 0 & 0 & 0 & 1 & 1 & 1 & 0 & 0 & 0 & 3 \\
\hline F3 & 1 & 0 & 0 & 0 & 0 & 0 & 0 & 0 & 0 & 1 & 0 & 0 & 0 & 0 & 1 & 0 & 0 & 3 \\
\hline F4 & 0 & 0 & 0 & 0 & 0 & 1 & 0 & 0 & 0 & 0 & 1 & 0 & 0 & 1 & 0 & 0 & 0 & 3 \\
\hline F5 & 0 & 0 & 1 & 0 & 0 & 1 & 0 & 0 & 0 & 1 & 0 & 0 & 0 & 1 & 0 & 0 & 0 & 4 \\
\hline F6 & 0 & 0 & 0 & 0 & 0 & 0 & 0 & 0 & 0 & 0 & 0 & 0 & 0 & 1 & 0 & 0 & 0 & 1 \\
\hline F7 & 0 & 0 & 0 & 0 & 0 & 0 & 0 & 0 & 1 & 1 & 0 & 0 & 0 & 0 & 1 & 0 & 1 & 4 \\
\hline F8 & 0 & 0 & 0 & 0 & 0 & 1 & 0 & 0 & 0 & 1 & 0 & 0 & 0 & 0 & 1 & 0 & 0 & 3 \\
\hline F9 & 0 & 0 & 0 & 0 & 0 & 0 & 0 & 1 & 0 & 0 & 0 & 0 & 0 & 0 & 0 & 0 & 0 & 1 \\
\hline F10 & 0 & 0 & 0 & 0 & 0 & 0 & 0 & 0 & 0 & 0 & 0 & 0 & 0 & 0 & 1 & 0 & 0 & 1 \\
\hline F11 & 1 & 1 & 1 & 0 & 0 & 0 & 0 & 1 & 0 & 1 & 0 & 0 & 0 & 1 & 1 & 0 & 0 & 7 \\
\hline F12 & 0 & 0 & 1 & 0 & 0 & 0 & 0 & 0 & 0 & 1 & 0 & 0 & 0 & 0 & 1 & 0 & 0 & 3 \\
\hline F13 & 1 & 0 & 1 & 0 & 0 & 0 & 0 & 0 & 0 & 1 & 0 & 0 & 0 & 0 & 1 & 0 & 0 & 4 \\
\hline F14 & 1 & 0 & 1 & 0 & 0 & 0 & 0 & 0 & 1 & 1 & 0 & 1 & 1 & 0 & 1 & 1 & 1 & 9 \\
\hline F15 & 0 & 0 & 0 & 0 & 0 & 0 & 0 & 0 & 0 & 1 & 0 & 1 & 1 & 1 & 0 & 1 & 0 & 5 \\
\hline F16 & 0 & 0 & 1 & 0 & 0 & 0 & 0 & 0 & 1 & 1 & 0 & 0 & 0 & 0 & 1 & 0 & 0 & 4 \\
\hline F17 & 0 & 0 & 0 & 0 & 0 & 0 & 0 & 0 & 1 & 0 & 0 & 0 & 0 & 0 & 0 & 0 & 0 & 1 \\
\hline Dependence & 4 & 1 & 6 & 0 & 0 & 3 & 0 & 2 & 4 & 10 & 1 & 3 & 3 & 7 & 10 & 2 & 2 & 58 \\
power & & & & & & & & & & & & & & \\
\hline
\end{tabular}

The level of factors is determined after the formation of the final reachability matrix. In the present study, the level of factors is obtained in three repetitions. Variables whose elements have a complete commonality between reachability set and antecedent set remain at level 1, and the remaining variables move to the next levels for classification. For example, for variable 1 , the reachability matrix consists of counting the number of $1 \mathrm{~s}$ in a row; this set represents criteria that are influenced by other criteria (13 criteria). In return, the antecedent matrix is obtained by counting the number of $1 \mathrm{~s}$ in the column that represents the criteria that affect the other criteria (all items). Similarly, these sets are also defined for other criteria. As shown in Table 5, factors 1, 3, 6, 8, 9, 10, 12, 13, 14, 15, 16, and 17 are at the first level.

Second-level elements are obtained by eliminating first-level factors and repeating these operations. According to Table 6, factors 2, 5, and 7 falls into the second level.

The third and final level elements are obtained by eliminating the second-level elements and repeating these operations. According to Table 7, factors 4 and 11 fall into the third level.

Finally, ISM is plotted after determining the level of factors and the relationship between them Figure 3.

\subsection{Factor Analysis Using MICMAC}

Step 3: The driving power diagram is plotted and the main factors and relationships between them are determined using the MICMAC analysis technique. According to the last row and column of Table 4, the influence-dependence power diagram is plotted as in Figure 4. 
Table 4. Final Reachability Matrix.

\begin{tabular}{|c|c|c|c|c|c|c|c|c|c|c|c|c|c|c|c|c|c|c|}
\hline & F1 & F2 & F3 & F4 & F5 & F6 & F7 & F8 & F9 & F10 & F11 & F12 & F13 & F14 & F15 & F16 & F17 & $\begin{array}{c}\text { Driving } \\
\text { Power }\end{array}$ \\
\hline $\mathrm{F} 1$ & 1 & 0 & $1 *$ & 0 & 0 & $1 *$ & 0 & $1 *$ & $1 *$ & $1 *$ & 0 & $1 *$ & $1 *$ & 1 & 1 & $1 *$ & $1 *$ & 12 \\
\hline F2 & $1 *$ & 1 & 1 * & 0 & 0 & 1 * & 0 & $1 *$ & $1 *$ & $1 *$ & 0 & 1 & 1 & 1 & $1 *$ & 1 * & $1 *$ & 13 \\
\hline F3 & 1 & 0 & 1 & 0 & 0 & $1 *$ & 0 & $1 *$ & 1 * & 1 & 0 & $1^{*}$ & $1 *$ & $1 *$ & 1 & $1 *$ & $1 *$ & 12 \\
\hline $\mathrm{F} 4$ & $1 *$ & $1 *$ & $1 *$ & 1 & 0 & 1 & 0 & $1 *$ & $1 *$ & $1 *$ & 1 & $1 *$ & $1 *$ & 1 & $1 *$ & $1 *$ & $1 *$ & 15 \\
\hline F5 & $1 *$ & 0 & 1 & 0 & 1 & 1 & 0 & $1 *$ & 1 * & 1 & 0 & $1 *$ & $1 *$ & 1 & $1 *$ & $1 *$ & $1 *$ & 13 \\
\hline F6 & $1 *$ & 0 & $1 *$ & 0 & 0 & 1 & 0 & $1 *$ & $1 *$ & $1 *$ & 0 & $1^{*}$ & 1 * & 1 & $1 *$ & $1 *$ & $1 *$ & 12 \\
\hline F7 & $1 *$ & 0 & $1 *$ & 0 & 0 & $1 *$ & 1 & $1 *$ & 1 & 1 & 0 & $1 *$ & $1 *$ & $1 *$ & 1 & $1 *$ & 1 & 13 \\
\hline F8 & $1 *$ & 0 & $1 *$ & 0 & 0 & 1 & 0 & 1 & $1 *$ & 1 & 0 & $1 *$ & $1 *$ & $1 *$ & 1 & $1^{*}$ & $1^{*}$ & 12 \\
\hline F9 & $1 *$ & 0 & $1 *$ & 0 & 0 & $1 *$ & 0 & 1 & 1 & $1 *$ & 0 & $1 *$ & $1 *$ & $1 *$ & $1 *$ & $1 *$ & $1 *$ & 12 \\
\hline F10 & $1 *$ & 0 & $1 *$ & 0 & 0 & $1^{*}$ & 0 & $1 *$ & $1^{*}$ & 1 & 0 & $1^{*}$ & $1 *$ & $1 *$ & 1 & $1 *$ & $1 *$ & 12 \\
\hline F11 & 1 & 1 & 1 & 0 & 0 & $1 *$ & 0 & 1 & $1 *$ & 1 & 1 & $1 *$ & $1 *$ & 1 & 1 & $1 *$ & $1 *$ & 14 \\
\hline F12 & $1 *$ & 0 & 1 & 0 & 0 & $1 *$ & 0 & $1 *$ & $1 *$ & 1 & 0 & 1 & $1 *$ & $1 *$ & 1 & $1 *$ & $1 *$ & 12 \\
\hline F13 & 1 & 0 & 1 & 0 & 0 & $1 *$ & 0 & $1 *$ & $1 *$ & 1 & 0 & $1^{*}$ & 1 & $1 *$ & 1 & $1 *$ & $1 *$ & 12 \\
\hline F14 & 1 & 0 & 1 & 0 & 0 & $1 *$ & 0 & $1 *$ & 1 & 1 & 0 & 1 & 1 & 1 & 1 & 1 & 1 & 12 \\
\hline F15 & $1 *$ & 0 & $1 *$ & 0 & 0 & $1 *$ & 0 & $1^{*}$ & $1 *$ & 1 & 0 & 1 & 1 & 1 & 1 & 1 & $1 *$ & 12 \\
\hline F16 & $1 *$ & 0 & 1 & 0 & 0 & $1 *$ & 0 & $1 *$ & 1 & 1 & 0 & $1 *$ & $1 *$ & $1 *$ & 1 & 1 & $1 *$ & 12 \\
\hline F17 & $1 *$ & 0 & $1 *$ & 0 & 0 & $1 *$ & 0 & 1 * & 1 & $1 *$ & 0 & $1 *$ & $1 *$ & $1 *$ & $1 *$ & $1 *$ & 1 & 12 \\
\hline $\begin{array}{l}\text { Dependence } \\
\text { power }\end{array}$ & 17 & 3 & 17 & 1 & 1 & 17 & 1 & 17 & 17 & 17 & 2 & 17 & 17 & 17 & 17 & 17 & 17 & 212 \\
\hline
\end{tabular}

Some 0 elements that have been converted to 1 are shown in the table with the symbol *.

Table 5. Leveling the criteria in the first step.

\begin{tabular}{|c|c|c|c|c|}
\hline Factor & Reachability Set & Antecedent Set (A) & Commonality & Level \\
\hline $\mathrm{F} 1$ & $1,3,6,8,9,10,12,13,14,15,16,17$ & All items & $1,3,6,8,9,10,12,13,14,15,16,17$ & 1 \\
\hline F2 & $1,2,3,6,8,9,10,12,13,14,15,16,17$ & $2,4,11$ & 2 & - \\
\hline F3 & $1,3,6,8,9,10,12,13,14,15,16,17$ & All items & $1,3,6,8,9,10,12,13,14,15,16,17$ & 1 \\
\hline $\mathrm{F} 4$ & $1,3,4,6,8,9,10,11,12,13,14,15,16,17$ & 4 & 4 & - \\
\hline F5 & $1,3,5,6,8,9,10,12,13,14,15,16,17$ & 5 & 5 & - \\
\hline F6 & $1,3,6,8,9,10,12,13,14,15,16,17$ & All items & $1,3,6,8,9,10,12,13,14,15,16,17$ & 1 \\
\hline F7 & $1,3,6,8,9,10,12,13,14,15,16,17$ & 7 & 7 & \\
\hline F8 & $1,3,6,8,9,10,12,13,14,15,16,17$ & All items & $1,3,6,8,9,10,12,13,14,15,16,17$ & 1 \\
\hline F9 & $1,3,6,8,9,10,12,13,14,15,16,17$ & All items & $1,3,6,8,9,10,12,13,14,15,16,17$ & 1 \\
\hline F10 & $1,3,6,8,9,10,12,13,14,15,16,17$ & All items & $1,3,6,8,9,10,12,13,14,15,16,17$ & 1 \\
\hline F11 & $1,3,6,8,9,10,11,12,13,14,15,16,17$ & 4,11 & 11 & - \\
\hline F12 & $1,3,6,8,9,10,12,13,14,15,16,17$ & All items & $1,3,6,8,9,10,12,13,14,15,16,17$ & 1 \\
\hline F13 & $1,3,6,8,9,10,12,13,14,15,16,17$ & All items & $1,3,6,8,9,10,12,13,14,15,16,17$ & 1 \\
\hline F14 & $1,3,6,8,9,10,12,13,14,15,16,17$ & All items & $1,3,6,8,9,10,12,13,14,15,16,17$ & 1 \\
\hline F15 & $1,3,6,8,9,10,12,13,14,15,16,17$ & All items & $1,3,6,8,9,10,12,13,14,15,16,17$ & 1 \\
\hline F16 & $1,3,6,8,9,10,12,13,14,15,16,17$ & All items & $1,3,6,8,9,10,12,13,14,15,16,17$ & 1 \\
\hline F17 & $1,3,6,8,9,10,12,13,14,15,16,17$ & All items & $1,3,6,8,9,10,12,13,14,15,16,17$ & 1 \\
\hline
\end{tabular}


Table 6. Leveling the criteria in the second step.

\begin{tabular}{ccccc}
\hline Factor & Reachability Set & Antecedent Set (A) & Commonality & Level \\
\hline F2 & 2 & $2,4,11$ & 2 & 2 \\
\hline F4 & 2,4 & 4 & 4 & - \\
\hline F5 & 5 & 5 & 5 & 2 \\
\hline F7 & 7 & 7 & 7 & 2 \\
\hline F11 & 2,11 & 4,11 & 1 & - \\
\hline
\end{tabular}

Table 7. Leveling the criteria in the third step.

\begin{tabular}{ccccc}
\hline Factor & Reachability Set & Antecedent Set (A) & Commonality & Level \\
\hline F4 & 4 & 4 & 4 & 3 \\
\hline F11 & 11 & 4,11 & 11 & 3 \\
\hline
\end{tabular}

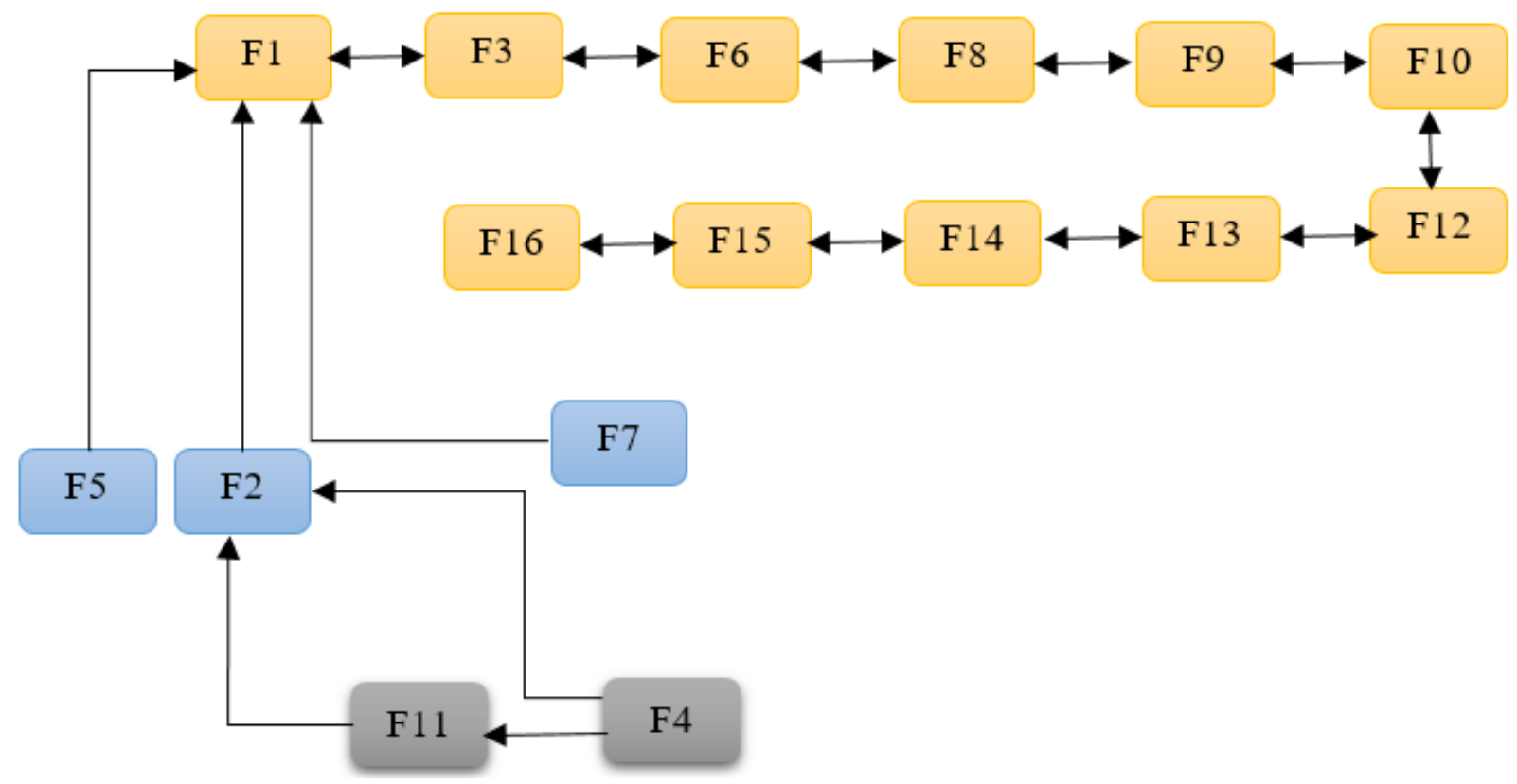

Figure 3. ISM graph.

According to Figures 3 and 4, the factors of F4 "government pressure or support" and F11 "area facilities", classified as independent variables, have the most significant effect on the success of foodservices. The factor of F4 "government pressure or support" directly affects the factors of F11 "area facilities" and F7 "competition". The factor of F11 "area facilities" directly affects the factor of F2 "area culture". These two factors, considered to be the main factors, have a major impact on the success of a foodservices and indirectly affect several factors. These factors have high driving power and at the same time weak dependence. After that, the influence of factors such as F2 "area culture", F9 "Foodservice size" and F17 "use of recyclable materials" are included as independent variables such as third-level factors. The remaining 12 factors are categorized in the first level as linkage variables. These factors have the least impact on the success of a unit despite their large number and complexity. These variables have high driving power as well as high dependence. Any changes in these variables cause changes in the entire system. No factors affect the success of these units as autonomous or dependent factors. 


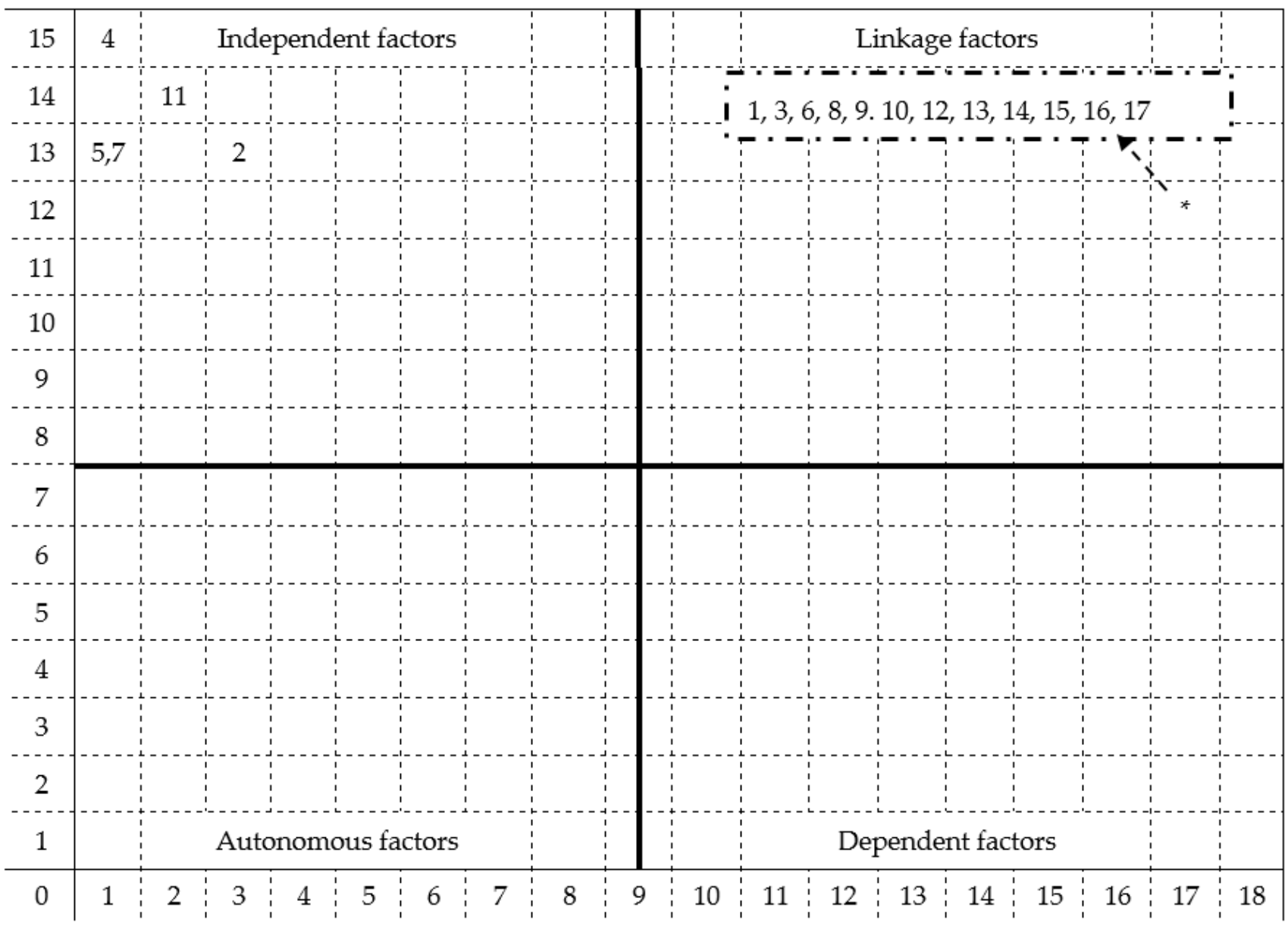

Figure 4. MICMAC analysis.

\subsection{IAPS and Ratings}

Step 4: IAPs are suggested by experts and rated using the S-DEA method. This step reduces uncertainty in macro decisions and the sustainable development of the industry. In the previous step, two factors, F4 "government pressure or support" and F11 "area facilities" were identified as root factors in foodservices. From the experts' point of view, nine suggested IAPs for the development of foodservices are presented in Table 8 .

Table 8. Ranking IAPs with S-DEA.

\begin{tabular}{lccccc}
\hline \multirow{2}{*}{ No. } & IAPs & \multicolumn{2}{c}{ Output } & \multirow{2}{*}{$\begin{array}{c}\text { Efficiency } \\
\text { Score }\end{array}$} & $\begin{array}{c}\text { Executive } \\
\text { Priority }\end{array}$ \\
\cline { 3 - 5 } AP1 & Main infrastructure: water, electricity, roads, internet, and parking & 0.97501 & 0.61291 & 0.97525 & 1 \\
\hline AP2 & Adopt financial and tax supportive laws & 0.97182 & 0.63945 & 0.97206 & 2 \\
\hline AP3 & Creating culture of healthy and organic food consumption & 0.97842 & 0.60702 & 0.97866 & 8 \\
\hline AP4 & Changes in decoration, size, and Foodservice location & 0.98078 & 0.58566 & 0.98102 & 4 \\
\hline AP5 & Training of staff and unit managers & 0.97418 & 0.63026 & 0.97442 & 7 \\
\hline AP6 & Local and media advertising & 0.98137 & 0.59654 & 0.98161 & 5 \\
\hline AP7 & Creating a material recycling unit & 0.97846 & 0.60568 & 0.9787 & 9 \\
\hline AP8 & Using healthy and organic materials & 0.97378 & 0.63674 & 0.97402 & 6 \\
\hline AP9 & healthy and sustainable menu/diet & 0.98008 & 0.58166 & 0.98004 & 3 \\
\hline
\end{tabular}


According to the results, AP1 is of the highest importance and has the highest priority. AP7 is also of the lowest importance. The AP1 improves the underlying infrastructure, including water, electricity, roads, internet, and parking, which should be the priority of the management team. The second way to improve is financial and tax supportive laws. Improvement of foodservices is a matter of serious concern when government supportive laws are enacted.

\section{Conclusions and Suggestions}

The purpose of this study is to provide an approach to identify and analyze the factors affecting the sustainable development of foodservices and to provide, improvement action plans in the city. For this purpose, the key factors for the development of these units are extracted using previous studies and expert opinions. Using the ISM method, the relationships between the factors are analyzed and the root factors are determined. According to experts' opinion, improvement action plans for root causes are developed and ranked by the slack-based DEA method. This reduces uncertainty in managers' decisions.

The proposed approach of this research was used in a case study on food service units in one of the cities of Iran. 17 effective factors in sustainable development were identified. The relationships between the factors affecting the growth and success of the units were analyzed and the two root factors of "area facilities" and" government pressure or support" were identified at the third (last) level. "Area culture", "Foodservice size", and "use of recyclable materials" are in the second level. Other factors were of low importance and were in the first level. Nine improvement action plans were introduced by experts. To reduce decision uncertainty, action plans were ranked by slack-based DEA method. Finally, the Action Plan "Main infrastructure: water, electricity, roads, internet and parking" and "Adopt financial and tax supportive laws" was identified to improve the performance of these units. The results of the current research on the development of environmental infrastructure and government support for food services are consistent with the results of some previous research, including Sagheer et al. Also, improvement action plans in the development of the main infrastructure of food services are consistent with the results of the study of Naeini et al.

For further research, it is recommended that this approach be developed to a larger industry with factors influencing the development of a region or country in the tourism industry. Due to the significant uncertainty caused by the Covid-19 pandemic, another important suggestion, is conducting study on the impact of the outbreak of this disease on the sustainability of food services and determining solutions to deal with this crisis.

Funding: This research received no external funding.

Informed Consent Statement: Not applicable.

Data Availability Statement: No new data were created or analyzed in this study. Data sharing is not applicable to this article.

Conflicts of Interest: The author declares no conflict of interest.

\section{References}

1. Fung, F.; Wang, H.-S.; Menon, S. Food safety in the 21st century. Biomed. J. 2018, 41, 88-95. [CrossRef] [PubMed]

2. Ionel, B. European regulation in the veterinary sanitary and food safety area, a component of the European policies on the safety of food products and the protection of consumer interests: A 2007 retrospective. Part two: Regulations. Universul Jurid. 2018, 16-19.

3. Rizou, M.; Galanakis, I.M.; Aldawoud, T.M.S.; Galanakis, C.M. Safety of foods, food supply chain and environment within the COVID-19 pandemic. Trends Food Sci. Technol. 2020, 102, 293-299. [CrossRef] [PubMed]

4. Veith, C. Industry 4.0 IT: Solutions in the Romanian Food Industry. J. Emerg. Trends Mark. Manag. 2018, 1, $221-230$.

5. Arata, L.; Fabrizi, E.; Sckokai, P. A worldwide analysis of trend in crop yields and yield variability: Evidence from FAO data. Econ. Model. 2020, 90, 190-208. [CrossRef]

6. Shalini, D.; Duggal, S. A review on food tourism quality and its associated forms around the world. Afr. J. Hosp. Tour. Leis. 2015, 4, 1-12. 
7. Aksoydan, E. Hygiene factors influencing customers'choice of dining-out units: Findings from a study of university academic staff. J. Food Saf. 2007, 27, 300-316. [CrossRef]

8. Sagheer, S.; Yadav, S.S.; Deshmukh, S.G. An application of interpretative structural modeling of the compliance to food standards. Int. J. Product. Perform. Manag. 2009, 58. [CrossRef]

9. Kumar, P.; Singh, R.K.; Kumar, R. An integrated framework of interpretive structural modeling and graph theory matrix approach to fix the agility index of an automobile manufacturing organization. Int. J. Syst. Assur. Eng. Manag. 2017, 8, 342-352. [CrossRef]

10. Bag, S.; Anand, N. Modelling barriers of sustainable supply chain network design using interpretive structural modelling: An insight from food processing sector in India. Int. J. Autom. Logist. 2015, 1, 234-255. [CrossRef]

11. Chaudhuri, A.; Srivastava, S.K.; Srivastava, R.K.; Parveen, Z. Risk propagation and its impact on performance in food processing supply chain. J. Model. Manag. 2016, 11. [CrossRef]

12. Sajid, Z.; Khan, F.; Zhang, Y. Integration of interpretive structural modelling with Bayesian network for biodiesel performance analysis. Renew. Energy 2017, 107, 194-203. [CrossRef]

13. Darbari, J.D.; Agarwal, V.; Sharma, R.; Jha, P.C. Analysis of impediments to sustainability in the food supply chain: An interpretive structural modeling approach. In Quality, IT and Business Operations; Springer: Berlin/Heidelberg, Germany, 2018 ; pp. 57-68.

14. Naeini, A.B.; Mosayebi, A.; Mohajerani, N. A hybrid model of competitive advantage based on Bourdieu capital theory and competitive intelligence using fuzzy Delphi and ism-gray Dematel (study of Iranian food industry). Int. Rev. 2019, 21-35. [CrossRef]

15. De Melo, F.J.C.; de Medeiros, D.D. Applying interpretive structural modeling to analyze the fundamental concepts of the management excellence model guided by the risk-based thinking of ISO 9001: 2015. Hum. Ecol. Risk Assess. Int. J. 2020, 1-31. [CrossRef]

16. Khan, W.; Akhtar, A.; Ansari, S.A.; Dhamija, A. Enablers of halal food purchase among Muslim consumers in an emerging economy: An interpretive structural modeling approach. Br. Food J. 2020, 122. [CrossRef]

17. Warfield, T.D.; Wild, J.J.; Wild, K.L. Managerial ownership, accounting choices, and informativeness of earnings. J. Account. Econ. 1995, 20, 61-91. [CrossRef]

18. Jadhav, J.R.; Mantha, S.S.; Rane, S.B. Development of framework for sustainable Lean implementation: An ISM approach. J. Ind. Eng. Int. 2014, 10, 72. [CrossRef]

19. Abuzeinab, A.; Arif, M.; Qadri, M.A. Barriers to MNEs green business models in the UK construction sector: An ISM analysis. J. Clean. Prod. 2017, 160, 27-37. [CrossRef]

20. Cherrafi, A.; Elfezazi, S.; Garza-Reyes, J.A.; Benhida, K.; Mokhlis, A. Barriers in Green Lean implementation: A combined systematic literature review and interpretive structural modelling approach. Prod. Plan. Control 2017, 28, 829-842. [CrossRef]

21. Faisal, M.N.; Talib, F. Implementing traceability in Indian food-supply chains: An interpretive structural modeling approach. $J$. Foodserv. Bus. Res. 2016, 19, 171-196. [CrossRef]

22. Charnes, A.; Cooper, W.W.; Rhodes, E. Measuring the efficiency of decision making units. Eur. J. Oper. Res. 1978, 2, 429-444. [CrossRef]

23. Foroughi, A.A.; Tavassoli, M.H. Discriminating extreme efficient decision making units in DEA using random weight vectors. Comput. Ind. Eng. 2019, 128, 305-312. [CrossRef]

24. Woo, C.; Chung, Y.; Chun, D.; Seo, H.; Hong, S. The static and dynamic environmental efficiency of renewable energy: A Malmquist index analysis of OECD countries. Renew. Sustain. Energy Rev. 2015, 47, 367-376. [CrossRef]

25. Zemtsov, S.; Kotsemir, M. An assessment of regional innovation system efficiency in Russia: The application of the DEA approach. Scientometrics 2019, 120, 375-404. [CrossRef]

26. Rezaee, M.J.; Yousefi, S.; Baghery, M.; Chakrabortty, R.K. An intelligent strategy map to evaluate improvement projects of Auto industry using fuzzy cognitive map and fuzzy slack-based efficiency model. Comput. Ind. Eng. 2020, 106920, in press. [CrossRef]

27. Thaivalappil, A.; Waddell, L.; Greig, J.; Meldrum, R.; Young, I. A systematic review and thematic synthesis of qualitative research studies on factors affecting safe food handling at retail and food service. Food Control 2018, 89, 97-107. [CrossRef]

28. Asadi, S.; Pourhashemi, S.O.; Nilashi, M.; Abdullah, R.; Samad, S.; Yadegaridehkordi, E.; Aljojo, N.; Razali, N.S. Investigating influence of green innovation on sustainability performance: A case on Malaysian hotel industry. J. Clean. Prod. 2020, 258, 120860. [CrossRef]

29. Hwang, J.; Choe, J.Y.J. Exploring perceived risk in building successful drone food delivery services. Int. J. Contemp. Hosp. Manag. 2019, 31. [CrossRef] 